\title{
Research on Comprehensive Evaluation Method of Distribution Automation Equipment Testing Results Based on Analytic Hierarchy Process and CRITIC Method
}

\author{
Youzhuo Zheng ${ }^{1 *}$, Yu Fu${ }^{1}$ and Xiaobing Xiao ${ }^{1}$ \\ ${ }^{1}$ Department Electric Power Research Institute of Guizhou Power Grid Co., Ltd., Guiyang, Guizhou, 550002, China
}

\begin{abstract}
To utilize the objective information of index data and consider the important role of subjective judgment in the evaluation of distribution automation equipment testing results, a comprehensive evaluation method based on AHP (Analytic Hierarchy Process) and CRITIC (CRiteria Importance Through Intercriteria Correlation) method is proposed. Firstly, an evaluation index system of distribution automation equipment testing results considering seven big indicators and thirty-six small indicators is established. Secondly, AHP and CRITIC method are adopted to solve a practical evaluation problem of distribution automation equipment testing results. The subjective weights of each evaluation index are calculated by AHP, the objective weights of each evaluation index are calculated by the CRITIC method. Then, to achieve the sorting of distribution automation equipment testing results accurately, the comprehensive weights are obtained by combining the two weights. Finally, the analysis and comparison of case studies show that the proposed evaluation index system can accurately reflect the performance of distribution automation equipment and the comprehensive evaluation method of distribution automation equipment testing results which comprehensively considers the subjective and objective weights can accurately output the comprehensive evaluation results.
\end{abstract}

\section{Introduction}

With the development of smart distribution network, the distribution automation equipment has also been widely popularized, and the number of distribution automation equipment is also increasing[1]. For the safety and reliability of smart distribution network, the high quality of the distribution automation equipment must be guaranteed[2]. At present, there are many problems in the management of distribution automation equipment: According to experience in practice, because of the different qualities in different corporations, there may be quality mistakes in distribution automation equipment productions. The quality of the distribution automation equipment cannot meet the requirements of the technical specifications[3]. Therefore, it is significant to reasonably evaluate the distribution automation equipment in ensuring the safe operation of the energy system. Both subjective and objective factors are fully utilized to make the weighting process more reasonable and output the accurate and comprehensive evaluation results of distribution automation equipment.

At present, the evaluation of distribution automation equipment testing results is mainly focused on the project itself, which has certain limitations[4]. The evaluation method of distribution automation equipment testing results generally include analytic hierarchy process[5] and fuzzy comprehensive evaluation[6]. When the single analytic hierarchy process is used to determine the weight, the weights are only determined by the subjective factors. The objectivity of the evaluation results is not enough[5]. Although the fuzzy comprehensive evaluation method has certain objectivity, the selection of membership function is also influenced by subjective factors, and the objectivity and accuracy of the evaluation results are easily affected by subjective factors[6].

In order to make full use of the objective information of index data and the important role of subjective judgment in the evaluation of distribution automation equipment testing results. Firstly, an evaluation index system of distribution automation equipment testing results considering seven big indicators and thirty-six small indicators is established. Then, AHP and CRITIC method are adopted to solve a practical evaluation problem of distribution automation equipment testing results. The subjective weights of each evaluation index are calculated by AHP[7], the objective weights of each evaluation index are calculated by CRITIC method[8]. Then, to achieve the sorting of distribution automation equipment testing results accurately, the comprehensive weights are obtained by combining the two weights. Finally, the effectiveness of the proposed method is verified by case studies. The results show that the accurate and comprehensive evaluation results of

*Corresponding author's e-mail: zyz199088@sina.com 
distribution automation equipment can be obtained by using the comprehensive weights combining the subjective weights and the objective weights.

\section{Evaluation index system of distribution automation equipment}

Considering that the distribution automation equipment testing results involve multiple indexes, an evaluation index system of distribution automation equipment testing results considering seven big indexes and thirtysix small indexes is established[9]. The evaluation index system is shown in Figure 1.

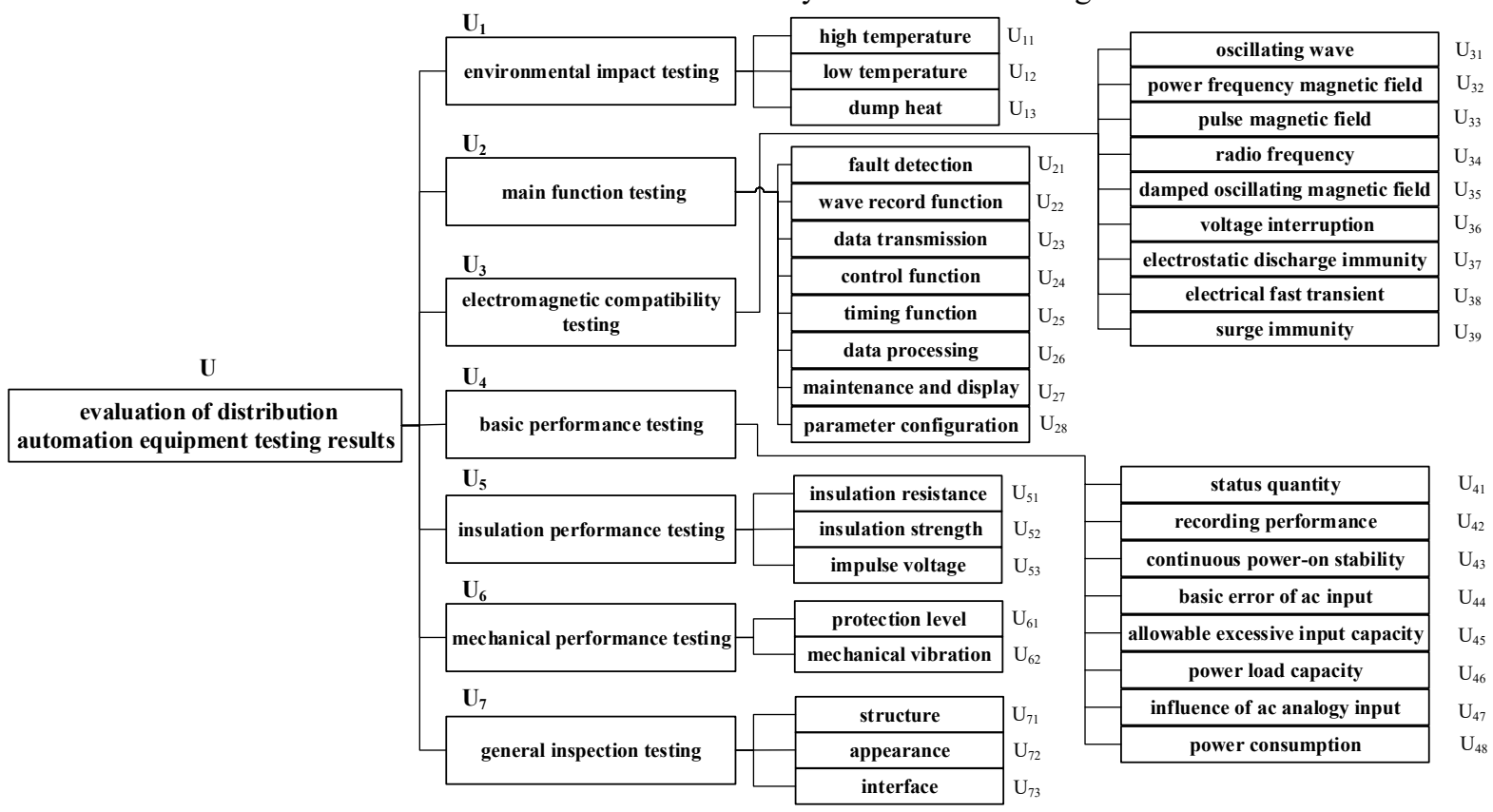

Figure 1. The evaluation index system of distribution automation equipment testing results

The first level evaluation index system involves seven big indexes (environmental impact testing, main function testing, electromagnetic compatibility testing, basic performance testing, insulation performance testing, mechanical performance testing, general inspection testing). The second level evaluation index system involves thirty-six small indexes. The environmental impact testing involves high temperature testing, low temperature testing, dump heat testing. The main function testing fault detection testing, wave record function testing, data transmission and storage testing, control function testing, timing function testing, data acquisition and processing function testing, maintenance and display function testing, parameter access and configuration function testing. The electromagnetic compatibility testing involves oscillating wave immunity testing, power frequency magnetic field immunity testing, pulse magnetic field immunity testing, radio frequency electromagnetic field radiation immunity testing, damped oscillating magnetic field immunity testing, voltage sag and short-term interruption testing, electrostatic discharge immunity testing, electrical fast transient pulse group immunity testing, surge immunity testing. The basic performance testing involves status quantity testing, recording performance testing, continuous power-on stability testing, basic error of ac input analogy quantity testing, allowable excessive input capacity of power frequency ac quantity testing, power load capacity testing, influence of ac analogy input testing, power consumption testing. The insulation performance testing involves insulation resistance testing, insulation strength testing, impulse voltage withstand testing. The structure and mechanical performance testing involves protection level testing, mechanical vibration testing. The general inspection testing involves equipment structure testing, equipment appearance testing, equipment interface testing.

\section{Calculation of comprehensive weights}

\subsection{Calculation of subjective weights}

The AHP (Analytic Hierarchy Process) has been widely used in the calculation of subjective weights. When the traditional AHP is used to calculate the subjective weights, the judgment matrix may not satisfy the consistency test[5]. In this paper, the improved AHP is used to solve the above problems[7]. The scale construction method is used to determine the judgment matrix, so the judgment matrix satisfies the consistency.

Firstly, according to expert opinions or user requirements, all the evaluation indexes are compared with each other, sorted by the undiminished degree of importance. Then, the index $x_{i}$ is compared with index $x_{i+1}$, and the corresponding scale value is denoted as $t_{i}$. Finally, the value of each element in the judgment matrix which satisfies the consistency can be calculated by the 
transitivity of the indexes importance. The judgment matrix $\mathrm{R}$ is shown in formula (1). The meaning of each scale value is shown in Table 1.

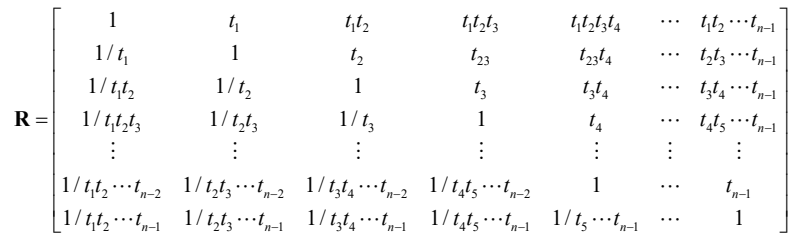

Table 1. The meaning of each scale value

\begin{tabular}{|c|c|}
\hline scale value & meaning \\
\hline 1 & equally important \\
\hline 1.2 & slightly important \\
\hline 1.4 & Strongly important \\
\hline
\end{tabular}

Based on the obtained judgment matrix, the subjective weights can be calculated by the formula (10) which is formulated as follows:

$$
w_{i}=\frac{\sqrt[n]{\prod_{j=1}^{n} r_{i j}}}{\sum_{i=1}^{n} \sqrt[n]{\prod_{j=1}^{n} r_{i j}}}
$$

where, $w_{i}$ is the subjective weight value of the $i$-th index; $r_{i j}$ is the value of the element in the $i$-th row and $j$-th column of judgment matrix

\subsection{Calculation of subjective weights}

To fully utilize the objective information of indexes data in the evaluation of distribution automation equipment testing results, the CRITIC method is used to determine the objective weights in this paper[6]. The CRITIC method not only considers the information of indexes data but also considers the contrast between different distribution automation equipment testing results. The objective weights calculated by the CRITIC method is more objective and reasonable.

The objective weights are calculated by the CRITIC method, each index is processed to become of the same direction. The positive index, bigger is better. The negative index, bigger is not better. The negative index can be converted into the positive index by the formula (3) which is formulated as follows:

$$
x_{i j}^{\prime}=\frac{1}{p+\max \left|X_{i}\right|+x_{i j}}
$$

where, $x_{i j}$ is the negative index; $x_{i j}^{\prime}$ is the negative index which is processed to become of the same direction or the positive index; $\max \left|X_{i}\right|$ is the maximum value of the $i$-th index; $p$ is the coordination coefficient.

The objective weights are calculated by the CRITIC method, each index is processed to become dimensionless. In this paper, we make indexes being dimensionless by the formula (4) which is formulated as follows:

$$
x_{i j}^{\prime \prime}=\frac{x_{i j}^{\prime}}{\sqrt{\sum_{j=1}^{m}\left(x_{i j}^{\prime}\right)^{2}}} \quad i=1,2, \cdots, n
$$

where, $x_{i j}^{\prime \prime}$ the index which is processed to become dimensionless, $m$ is the number of distribution automation equipment that need to be evaluated

Finally, each index has been processed to become of the same direction and dimensionless. The objective weights can be calculated by the formula (5) which is formulated as follows:

$$
\left\{\begin{array}{l}
s_{i}=\sqrt{\frac{1}{m} \sum_{j=1}^{m}\left(x_{i j}^{\prime \prime}-\bar{x}_{i}^{\prime \prime}\right)^{2}} \quad i=1,2, \cdots, n \\
\rho_{i j}=\operatorname{cov}\left(X_{i}^{\prime \prime}, X_{j}^{\prime \prime}\right) /\left(s_{i} s_{j}\right) \quad i, j=1,2, \cdots, n \\
G_{i}=s_{i} \sum_{j=1}^{n}\left(1-\rho_{i j}\right) \quad i=1,2, \cdots, n \\
v_{i}=\frac{G_{i}}{\sum_{j=1}^{n} G_{j}}
\end{array}\right.
$$

where, $v_{i}$ is the objective weight value of the $i$-th index; $\mathrm{n}$ is the total number of indexes; $s_{i}$ is the standard deviation of the $i$-th index; $\rho_{i j}$ is The correlation coefficient between the $i$-th index and the $j$-th index; $G_{i}$ is the information of the $i$-th index; $\operatorname{cov}\left(X_{i}^{\prime \prime}, X_{j}^{\prime \prime}\right)$ is the Covariance between the $i$-th row and the $j$-th row of matrix $X^{\prime \prime}$. It should be noted that when the standard deviation of the $i$-th index is zero, the $i$-th objective weight cannot be obtained.

\subsection{Calculation of comprehensive weights}

To achieve the sorting of distribution automation equipment testing results accurately, the comprehensive weights are obtained by combining the subjective weights and the objective weights. the comprehensive weights can be calculated by the formula (6) which is formulated as follows:

$$
a_{i}=\frac{\sqrt{w_{i} v_{i}}}{\sum_{j=1}^{n} \sqrt{w_{j} v_{j}}}
$$

where, $a_{i}$ is the comprehensive weight value of the $i$-th index. it should be noted that when the standard deviation of the $i$-th index is zero, the $i$-th comprehensive weight is equal to the $i$-th subjective weight.

\section{Solution methodology}

According to the above algorithm, the flow chart of the comprehensive evaluation method of distribution automation equipment testing results based on AHP (Analytic Hierarchy Process) and CRITIC (CRiteria Importance Through Intercriteria Correlation) method is shown in Figure 2. The specific operation process 
includes ten steps: (1)basic data inputting; (2)calculation of the judgment matrix; (3)calculation of the normalized test results matrix; (4)calculation of the subjective weights; (5)calculation of the objective weights; (6) calculation of the comprehensive weights; (7) the second level evaluation results matrix outputting; 8)calculation of the judgment matrix; 9)calculation of the subjective weights; (10)results outputting.

\begin{tabular}{|c|}
\hline Calculate the judgment matrix R1-R7 \\
\hline Calculate the normalized test results matrix \\
\hline Calculate the subjective weights $W\left(U_{1}\right)-W\left(U_{7}\right)$ \\
\hline Calculate the comprehensive weights $A\left(U_{1}\right)-A\left(U_{7}\right)$ \\
\hline Output the second level evaluation results matrix $\mathrm{B}_{2}$ \\
\hline \\
Calculate the judgment matrix $\mathrm{R}_{(\mathrm{U})}$ \\
\hline \\
Calculate the subjective weights $W(U)$ \\
\hline \\
Output the evaluation results $\mathrm{B}_{1}$ \\
\hline \\
\hline \\
\hline \\
\hline \\
\hline
\end{tabular}

Figure 2. Flow chart of the comprehensive evaluation method of distribution automation equipment based on AHP and CRITIC method

\section{Results \& Discussion}

In this paper, the analysis and comparison of case studies are based on the test results of two power distribution automation equipment. According to expert opinions or user requirements, the scale value can be determined. For judgment matrix $\mathbf{R} 1$, the sorting of the importance of the environmental impact testing indexes: high temperature testing $=$ low temperature testing $>$ dump heat testing. For judgment matrix R2, the sorting of the importance of the main function testing indexes: fault detection testing $=$ wave record function testing $>$ data transmission and storage testing $=$ control function testing $=$ timing function testing $=$ data acquisition and processing function testing $>$ maintenance and display function testing= parameter access and configuration function testing. For judgment matrix R3, the sorting of the importance of the electromagnetic compatibility testing indexes: oscillating wave immunity testing $=$ power frequency magnetic field immunity testing $=$ pulse magnetic field immunity testing $=$ radio frequency electromagnetic field radiation immunity testing $=$ damped oscillating magnetic field immunity testing $>$ voltage sag and short-term interruption testing $=$ electrostatic discharge immunity testing $=$ electrical fast transient pulse group immunity testing= surge immunity testing. For judgment matrix R4, the sorting of the importance of the basic performance testing indexes: status quantity testing = recording performance testing $>$ continuous power-on stability testing $=$ basic error of ac input analogy quantity testing = allowable excessive input capacity of power frequency ac quantity testing $>$ power load capacity testing $>$ influence of ac analogy input testing $=$ power consumption testing. For judgment matrix R5, the sorting of the importance of the insulation performance testing indexes: insulation resistance testing $=$ insulation strength testing $>$ impulse withstand voltage testing. For judgment matrix R6, the sorting of the importance of the structure and mechanical performance testing indexes: protection level testing = mechanical vibration testing. For judgment matrix R7, the sorting of the importance of the general inspection testing indexes: equipment structure testing $>$ equipment appearance testing=equipment interface testing. If the distribution automation equipment is used in special situations, the order of indexes importance should be changed.

Table 2. The scale value of the judgment matrix R1-R7

\begin{tabular}{|c|c|c|c|c|c|c|c|}
\hline $\begin{array}{c}\text { scale } \\
\text { value }\end{array}$ & $\mathbf{R} 1$ & $\mathbf{R} 1$ & $\mathbf{R} 1$ & $\mathbf{R} 1$ & $\mathbf{R} 1$ & $\mathbf{R} 1$ & $\mathbf{R} 1$ \\
\hline $\mathrm{t} 1$ & 1 & 1 & 1 & 1 & 1 & 1 & 1.2 \\
\hline $\mathrm{t} 2$ & 1.2 & 1.2 & 1 & 1.2 & 1 & & 1 \\
\hline $\mathrm{t} 3$ & & 1 & 1 & 1 & & & \\
\hline $\mathrm{t} 4$ & & 1 & 1 & 1 & & & \\
\hline $\mathrm{t} 5$ & & 1 & 1.2 & 1.2 & & & \\
\hline $\mathrm{t} 6$ & & 1.4 & 1 & 1.2 & & & \\
\hline $\mathrm{t} 7$ & & 1 & 1 & 1 & & & \\
\hline $\mathrm{t} 8$ & & & 1 & & & & \\
\hline
\end{tabular}

Based on the corresponding scale value, the judgment matrix $\mathbf{R} 1 \sim \mathbf{R} 7$ can be calculated by the formula (1). 


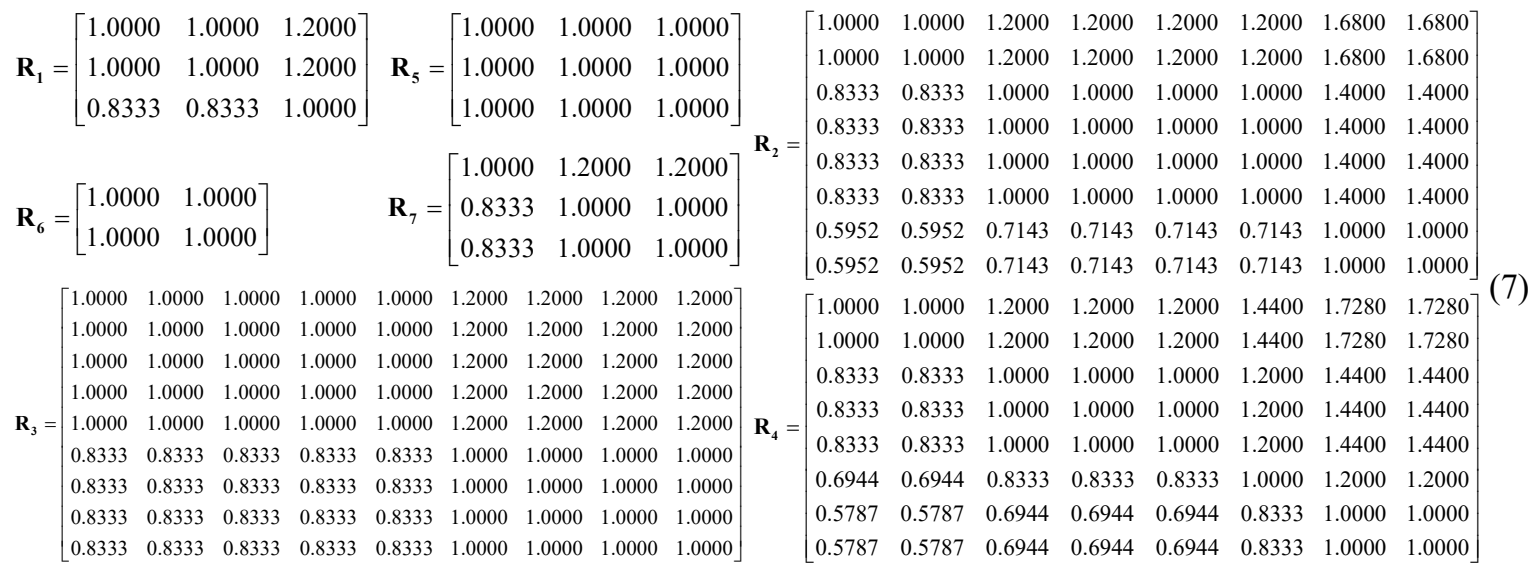

Based on the obtained judgment matrix R1-R7, the subjective weights $W\left(U_{1}\right)-W\left(U_{7}\right)$ can be calculated by the formula (2). $\quad W\left(U_{1}\right)=[0.3529, \quad 0.3529, \quad 0.2941]^{\mathrm{T}}$, $W\left(U_{2}\right)=[0.1533,0.1533,0.1277,0.1277,0.1277,0.1277$, $0.0912, \quad 0.0912]^{\mathrm{T}}, \quad W\left(U_{3}\right)=\left[\begin{array}{lll}0.1200, & 0.1200, & 0.1200,\end{array}\right.$

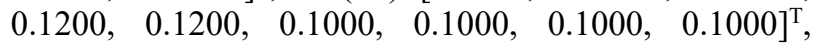
$W\left(U_{4}\right)=[0.1574,0.1574,0.1312,0.1312,0.1312,0.1093$, $0.0911, \quad 0.0911]^{\mathrm{T}}, \quad W\left(U_{5}\right)=\left[\begin{array}{lll}0.3333, & 0.3333, & 0.3333\end{array}\right]^{\mathrm{T}}$,

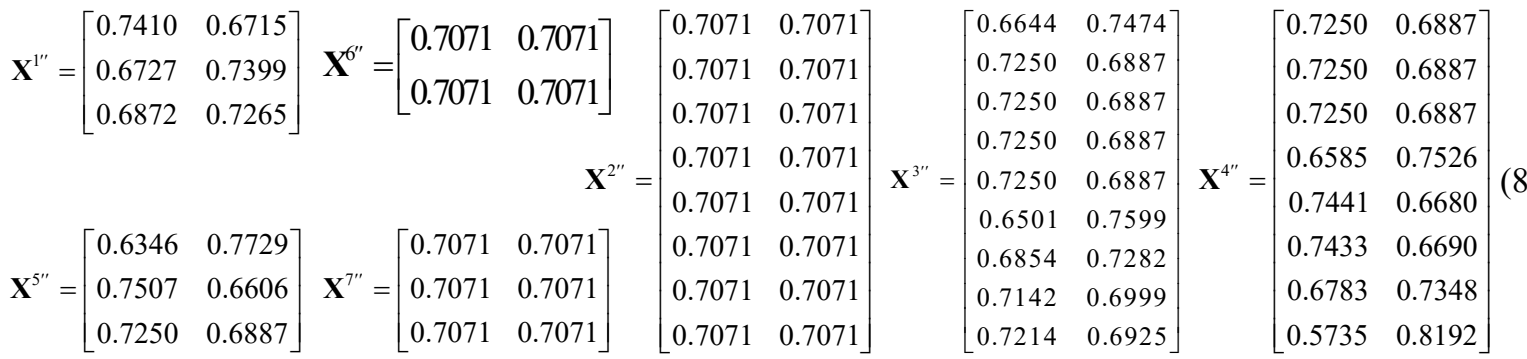

$W\left(U_{6}\right)=[0.5000, \quad 0.5000]^{\mathrm{T}}, \quad W\left(U_{7}\right)=[0.3750, \quad 0.3125$, $0.3125]^{\mathrm{T}}$.

Based on the test results of two power distribution automation equipment, each index is processed to become dimensionless and of the same direction by the formula (3) and formula (4). The normalized test results matrix $\mathbf{X}^{\prime \prime}$ are shown in (8).

$$
\mathbf{B}_{2}=\left[\begin{array}{ll}
0.7072 & 0.7056 \\
0.7071 & 0.7071 \\
0.6925 & 0.7201 \\
0.6778 & 0.7302 \\
0.6858 & 0.7240 \\
0.7071 & 0.7071 \\
0.7071 & 0.7071
\end{array}\right]
$$

For The first level evaluation index system judgment matrix $\mathbf{R}_{(U)}$, the sorting of the importance of the environmental impact testing indexes: (environmental impact testing=main function testing=electromagnetic compatibility testing=basic performance testing=electric pressure insulation performance testing $>$ structure and mechanical performance testing $>$ general inspection testing). Then the scale value can be determined. $\mathrm{t} 1=1$, $\mathrm{t} 2=1, \quad \mathrm{t} 3=1, \mathrm{t} 4=1, \mathrm{t} 5=1.6, \quad \mathrm{t} 6=1.8$. Based on the corresponding scale value, the judgment matrix $\mathbf{R}_{(U)}$ can be calculated by the formula (1). 


$$
\mathbf{R}_{(U)}=\left[\begin{array}{lllllll}
1.0000 & 1.0000 & 1.0000 & 1.0000 & 1.0000 & 1.6000 & 2.8800 \\
1.0000 & 1.0000 & 1.0000 & 1.0000 & 1.0000 & 1.6000 & 2.8800 \\
1.0000 & 1.0000 & 1.0000 & 1.0000 & 1.0000 & 1.6000 & 2.8800 \\
1.0000 & 1.0000 & 1.0000 & 1.0000 & 1.0000 & 1.6000 & 2.8800 \\
1.0000 & 1.0000 & 1.0000 & 1.0000 & 1.0000 & 1.6000 & 2.8800 \\
0.6250 & 0.6250 & 0.6250 & 0.6250 & 0.6250 & 1.0000 & 1.8000 \\
0.3472 & 0.3472 & 0.3472 & 0.3472 & 0.3472 & 0.5556 & 1.0000
\end{array}\right]
$$

Based on the obtained judgment matrix $\mathbf{R}_{(U)}$, the subjective weights $W(U)$ can be calculated by the formula (2). $W(U)=[0.1674,0.1674,0.1674,0.1674$, $0.1674,0.1047,0.0581]^{\mathrm{T}}$. Then the first level evaluation results matrix $\mathbf{B}_{1}$ can be calculated by $t$ he second level evaluation results matrix $\mathbf{B}_{2}$ and the subjective weights $W(U) . \mathbf{B}_{1}=[0.6962,0.7157]$. The evaluation result of No. 1 distribution automation equipment is equal to 0.6962 , The evaluation result of No. 2 distribution automation equipment is equal to 0.7157 . By contrast, No. 2 distribution automation equipment is better than No. 1 distribution automation equipment. Table 3 shows that compared with AHP, the proposed method can obtain an accurate and comprehensive evaluation result. Because the comprehensive weights calculated by combining the subjective weights and the objective weights are more reasonable and scientific, the proposed method has the advantage that both the objective information of index data and the important role of subjective judgment are fully utilized.

Table 3. The meaning of each scale value

\begin{tabular}{|c|c|c|}
\hline Method & $\begin{array}{c}\text { No. 1 distribution } \\
\text { automation } \\
\text { equipment }\end{array}$ & $\begin{array}{c}\text { No. 2 distribution } \\
\text { automation } \\
\text { equipment }\end{array}$ \\
\hline AHP & 0.7044 & 0.7084 \\
\hline $\begin{array}{c}\text { Proposed } \\
\text { method }\end{array}$ & 0.6962 & 0.7157 \\
\hline
\end{tabular}

\section{Conclusion}

This paper proposes a comprehensive evaluation method of distribution automation equipment testing results based on AHP (Analytic Hierarchy Process) and CRITIC (CRiteria Importance Through Intercriteria Correlation) method. AHP (the method of calculating the subjective weights) and the CRITIC method (the method of calculating the objective weights) are adopted for the evaluation of distribution automation equipment testing results, so both the objective information of index data and the important role of subjective judgment are fully utilized. Compared with the subjective weights calculated by AHP, the comprehensive weights calculated by combining the subjective weights and the objective weights are more reasonable and scientific. The effectiveness of the comprehensive evaluation method of distribution automation equipment testing results is verified by the analysis and comparison of case studies. The results show that the more accurate and comprehensive evaluation results can be obtained by the proposed comprehensive evaluation index system and the proposed evaluation method of distribution automation equipment testing results which comprehensively consider the subjective and objective weights.

\section{Acknowledgments}

This work is supported by Projects of Department Electric Power Research Institute of Guizhou Power Grid Co., Ltd. (066600KK52180058).

\section{References}

1. Zhao J., CHEN X., LIN T., et al. (2012) Distribution automation construction in smart grid. Automation of Electric Power Systems, 36: 33-36 (in Chinese).

2. Wang Y. (2010) Research framework of technical standard system of strong \& smart grid. Automation of Electric Power Systems, 34: 1-6 (in Chinese).

3. Cai J., Yang C. (2018) Study on distribution automation terminal state evaluation method based on analytic hierarchy process. Guangxi Electric Power, 41: 6-9 (in Chinese).

4. Yin H., Fu J., Shi C., et al. (2020) Full process quality comprehensive evaluation system and method of distribution automation terminals. Electric Power Information and Communication Technology, 18: 9-13 (in Chinese).

5. Zhou Y., Wei F. (2007) Combination weighting approach in performance evaluation of enterprise. Industrial Engineering and Management, 4): 51-54 (in Chinese).

6. Zhang P., Ling W., Zheng Y., (2016) Research on the evaluation method of distribution automation operation based on fuzzy analytic hierarchy process. Electrical Measurement and Instrumentation, 53: 7277 (in Chinese).

7. Li N., He Z., (2009) Power quality comprehensive evaluation combining subjective weight with objective weight. Power System Technology, 33: 55-61 (in Chinese).

8. Diakoulaki D., Mavrotass G., Papayannakis L., (1995) Determining objective weights in multiple criteria problems: the critic method, 22: 763-770.

9. Zhang B., Zhao J., Lin T., et al. (2014) Research and establishment of standard system for distribution automation system. Distribution \& Utilization, 31: 25-28 (in Chinese). 